\title{
As percepções dos egressos do Pibid da área de Ciências da Natureza: implicações do programa na formação docente
}

\author{
The perceptions of Pibid graduates from the Nauture Sciences area: implications \\ of the program on teacher education
}

\author{
Tailine Penedo Batista ${ }^{1}$ \\ Eliane Gonçalves dos Santos ${ }^{2}$
}

\begin{abstract}
Resumo
O objetivo da presente pesquisa foi investigar as percepções dos egressos do Programa Institucional de Bolsas de Iniciação à Docência (Pibid) da área de Ciências da Natureza em relação às contribuições que o programa teve na sua formação inicial e na sua constituição identitária docente. A presente pesquisa utiliza o método qualitativo e foi realizada na Biblioteca Digital Brasileira de Teses e Dissertações (BDTD), do Instituto Brasileiro de Informação em Ciência e Tecnologia (IBICT). O processo metodológico consistiu em investigar os trabalhos acadêmicos brasileiros (teses e dissertações) disponíveis na BDTD utilizando como palavra-chave "egressos pibid", para isso foi selecionado os anos de 2015-2019. Após selecionarmos os trabalhos que contemplavam o objetivo da pesquisa, realizou-se a análise de conteúdo. A partir da pesquisa realizada, destacamos que o programa apresenta contribuições positivas para os egressos da área de Ciências da Natureza, fornecendo subsídios para constituição da identidade docente de um professor reflexivo.
\end{abstract}

Palavras-chave: Formação inicial. Constituição identitária. Autonomia. Formação continuada.

\begin{abstract}
The objective of this research was to investigate the perceptions of the graduates of the Institutional Program for Teaching Initiation Scholarships (Pibid) in the area of Natural Sciences in relation to the contributions that the program had in its initial formation and in its teaching identity constitution. This research uses the qualitative method and was carried out at the Brazilian Digital Library of Theses and Dissertations (BDTD), of the Brazilian Institute of Information in Science and Technology (IBICT). The methodological process consisted of investigating the Brazilian academic works (theses and dissertations) available at BDTD using the keyword "pibid graduates", for which the years 2015-2019 were selected. After selecting the works that contemplated the research

\footnotetext{
1 Graduada em Licenciatura em Ciências Biológicas pela Universidade Federal da Fronteira Sul (UFFS), campus Cerro Largo, RS. E-mail: tailinepenedo@gmail.com

2 Doutora em Educação nas Ciências. Docente do Curso de Ciências Biológicas - Licenciatura e do Programa de Pós-Graduação no Ensino de Ciências (PPGEC) da Universidade Federal da Fronteira Sul (UFFS), campus Cerro Largo, RS. E-mail: eliane.santos@uffs.edu.br
} 


\section{-Revista de Iniciação à Docência, v.6, n.2, 2021- \\ Publicação: dezembro, 2021 - ISSN 2525-4332}

objective, content analysis was performed. From the research carried out, we highlight that the program presents positive contributions for graduates in the area of Natural Sciences, providing subsidies for the constitution of the teaching identity of a reflective teacher.

Keywords: Initial formation. Identity constitution. Autonomy. Continued formation.

\section{Introdução}

A formação do professor está alicerçada em um conjunto de processos contínuos de desenvolvimento pessoal, profissional e social que são construídos a partir das experiências, vivências e reflexões acerca da profissão e não somente pela formação na Universidade (SILVA, 2011).

Apesar dos inúmeros processos envolvidos na formação de um professor, acreditamos que a fase de formação inicial, que se dá na graduação, é um importante aliado para o seu desenvolvimento profissional. Consideramos que o professor representa um papel imprescindível no processo de mudança social e, também por isso, é importante um investimento mais substancial nessa formação, uma vez que o processo de melhoria do ensino depende também da atuação do professor (DELIZOICOV et al., 2002).

No que tange ao ensino de Ciências da Natureza, a formação de professores exige uma profissionalização que promova a contextualização da aprendizagem, a apropriação de conhecimentos com significado e a busca do desenvolvimento de capacidades necessárias para a compreensão da sociedade e do ensino.

Nesse sentido, o Programa Institucional de Bolsas de Iniciação à Docência (Pibid) é um forte aliado da educação, pois oferece aos professores uma formação de qualidade.

O programa é uma iniciativa da Coordenação de Aperfeiçoamento de Pessoal de Nível Superior (CAPES) e visa fomentar e valorizar o processo formativo de professores (CAPES, 2008). Segundo seus idealizadores, o Pibid oportuniza uma experiência formativa desde o início do curso, subsidiando a formação docente de qualidade, que valoriza a prática e possibilita uma interação entre professores em formação inicial e continuada. Desse modo, o programa tem grande possibilidade de contribuir para o desenvolvimento crítico e reflexivo acerca das atividades desenvolvidas.

A dinâmica do Pibid oferece aos licenciandos a inserção nas escolas, nas quais estes irão atuar como professores em formação inicial. O programa é uma oportunidade de inovar a práxis docente. De acordo com Pimenta (1994) a práxis diz respeito à educação como uma prática social e transformadora que se fundamenta na teoria e na a prática e que coloca o aluno como ativo nos processos de ensino e de aprendizagem. 


\section{-Revista de Iniciação à Docência, v.6, n.2, 2021- \\ Publicação: dezembro, 2021 - ISSN 2525-4332}

Sendo assim, o Pibid favorece a construção da práxis na medida em que favorece o trabalho coletivo, no qual todos os envolvidos interagem entre si para uma formação de qualidade (CAPES, 2008).

Nesse viés, o programa se destaca como um subsídio para fortalecer o papel da Escola Básica e contribuir para o desenvolvimento profissional dos docentes numa perspectiva teórica e prática (GATTI et al., 2014). Ademais, o Pibid pode ser organizado de forma a oferecer uma formação pautada nos processos de reflexão-ação-reflexão como pressuposto fundamental para o desenvolvimento das atividades (FELíCIO, 2014).

Para um curso de formação de professores, estar envolvido em programas como o Pibid é fundamental, pois, a partir desse são realizadas atividades, diálogos e reflexão que enriquecem o percurso formativo do docente. Compreende-se que o Pibid é um espaço privilegiado para a pesquisa e investigação da prática, incentivando também o envolvimento do professor em formação inicial no cotidiano da escola, diminuindo assim, "as distâncias que ocorrem na passagem da condição de aluno para a condição de professor" (SOCZEK, 2011, p.61).

Além de toda a contribuição para formação inicial dos professores, o Pibid traz outra contribuição muito importante: trata-se da aproximação da instituição formadora a Universidade - e a instituição na qual os egressos irão atuar. Isso acontece em função da parceria entre a universidade e a escola, que se estabelece ao longo do programa.

Em relação ao processo de formação de professores, Imbernón (2001, p. 15) destaca que:

[...] a formação assume um papel que transcende o ensino que pretende uma mera atualização científica, pedagógica e didática e se transforma na possibilidade de criar espaços de participação, reflexão e formação para que as pessoas aprendam e se adaptem para poder conviver com a mudança e as incertezas.

Como destacado pelo autor, a formação de professores deve criar espaços de novos aprendizados, pautados na reflexão e no diálogo coletivo, refletindo assim, sobre as transformações necessárias ao processo de ensinar e também sobre o papel do professor nesse processo. Dessa maneira, em relação à formação inicial, o Pibid, as práticas de ensino e o estágio supervisionado, apresentam a função de inserirem os licenciando nas escolas e provocar nestes esta reflexão, já no início do curso.

Porém, Pimenta (2007) adverte que na maioria das vezes os estágios supervisionados, os quais são os espaços nos cursos de licenciatura destinados para aproximar o professor em formação inicial da Escola Básica estão envolvidos em processos mais burocráticos, distanciando assim da realidade da escola e contribuindo pouco para a identidade profissional do docente.

Dessa forma, o Pibid distingue-se do estágio supervisionado, por diversos motivos, entre estes pode-se apontar que,

[...] o estágio tem início apenas no segundo ano do curso de licenciatura, ao contrário do Pibid, cuja inserção do licenciando já é possível no primeiro ano. Tal 


\section{-Revista de Iniciação à Docência, v.6, n.2, 2021- Publicação: dezembro, 2021 - ISSN 2525-4332}

organização do estágio confirma a dicotomia entre teoria e prática, imprimindo na primeira maior importância ao processo de formação. Os estágios geralmente são realizados sem a efetiva aproximação pedagógica da IES com as escolas. São os alunos que procuram as escolas para executar o cumprimento das atividades orientadas do estágio, fomentando aspecto individualista na realização da atividade, diferentemente do Pibid, que tem como princípio o trabalho coletivo e colaborativo (NOFFS; RODRIGUES, 2016, p.368).

Assim, o Pibid está sendo um complementador da formação inicial, preenchendo algumas lacunas que o estágio supervisionado deixa e aproximando já nas primeiras etapas da graduação o licenciando da realidade escolar. O Pibid apresenta um diferencial dos estágios supervisionados, pois o programa incentiva a participação ativa em eventos científicos, feiras, seminários e congressos, motivando seus participantes a compartilharem conhecimento e enriquecer seus currículos e seu desenvolvimento profissional e pessoal.

Nessa perspectiva, os egressos do programa desenvolvem uma formação que aproxima a teoria (conteúdos aprendidos) e a prática (docência), sob um viés colaborativo, no qual o coletivo se ajuda. A experiência dos egressos no Pibid também possibilita uma formação pautada na reflexão, de modo que as práticas realizadas enquanto bolsistas de iniciação à docência, proporcionam uma reflexão a partir da ação.

As vivências no Pibid marcam de forma positiva os licenciandos, pois por meio dessas é possível desenvolver o senso crítico e a certeza de permanecer ou evadir da docência, além de incentivar às práticas de escrita de relato de experiência e participação em eventos científicos, a fim de divulgar as práticas realizadas e inspirar os professores em formação inicial e continuada à diversificarem suas aulas e incentivando os professores das Escolas Básicas a continuarem sua formação.

Desse modo, evidencia-se a importância do programa na aproximação do licenciando com a Escola Básica e no incentivo à formação continuada, compreendendo que:

a docência é uma profissão complexa e, tal como as demais profissões, é aprendida. Os processos de aprender a ensinar, de aprender a ser professor e de se desenvolver profissionalmente são lentos. Iniciam-se antes do espaço formativo das licenciaturas e prolongam-se por toda a vida (MIZUKAMI, 2013, p.23)

Nesse sentido, a presente pesquisa objetiva investigar e analisar as Teses e Dissertações que tratam sobre os egressos do Pibid da área de Ciências da Natureza, procurando identificar as contribuições que o programa teve na sua formação inicial e na sua constituição identitária docente.

\section{Metodologia}

O presente trabalho utiliza o método qualitativo, no qual foi realizado uma análise documental (LÜDKE; ANDRÉ, 2013), buscou-se analisar os dados obtidos nos trabalhos que compõem o corpus da pesquisa. 
Em um primeiro momento investigamos os trabalhos acadêmicos brasileiros (teses e dissertações) disponíveis na Biblioteca Digital Brasileira de teses e dissertações (BDTD), do Instituto Brasileiro de Informação em Ciência e Tecnologia (IBICT)3, pois a plataforma dispõe de um catálogo completo de teses e dissertações desenvolvidas no país, as quais são encontradas de forma integral.

Para a seleção observou-se nos títulos, resumos e palavras-chave, o termo "egressos do Pibid", tendo como foco a área da Ciências da Natureza, no período entre 2015 a 2019, pois esse período foi o de maior publicação de editais de bolsas do Pibid. Utilizamos como critério de seleção, os trabalhos que continham o termo "egressos do Pibid" no título, resumo e/ou palavra-chave.

Após a seleção dos trabalhos que contemplavam o objetivo da presente pesquisa, realizou-se o processo de análise, o qual foi embasado na Análise de Conteúdo na perspectiva de Bardin (2011) que compreende: 1. A pré análise, a qual consiste em leitura, formulação das hipóteses e dos objetivos, constituição do corpus da pesquisa e preparação do material; 2. A exploração do material, nessa fase é realizada a administração da técnica sobre o corpus (codificação); e, por fim, 3. O tratamento dos resultados, no qual é realizado a seleção dos resultados e as interpretações.

A partir da análise emergiram duas categorias a saber: I) Desenvolvimento da identidade profissional docente e II) O Pibid como incentivo à formação acadêmica e profissional. Para facilitar a compreensão, os trabalhos de dissertações e teses utilizados para a pesquisa, estão nominados, como D1, D2, D3,..., D7 para dissertações; T1, T2 e T3 para teses, e seus dados estão apresentados em destaque, em itálico e entre aspas.

\section{Resultado e Discussão}

Dos quarenta e cinco (45) trabalhos de dissertações e teses encontrados ao utilizarmos o descritor "egressos do Pibid" na plataforma da BDTD, dez (10) abordavam sobre as percepções dos egressos do Pibid da área de Ciências da Natureza em relação às contribuições que o programa proporciona para a formação docente, e foram selecionadas para a análise (quadro 1).

Quadro 1: Trabalhos selecionados na plataforma BDTD.

\begin{tabular}{|l|l|}
\hline Codificação & Referência do Trabalho \\
\hline D1 & $\begin{array}{l}\text { ARAÚJO, Adriana Castro. Avaliação do Programa Institucional de Bolsa de Iniciação à } \\
\text { Docência da Universidade Federal do Ceará na perspectiva dos egressos. 2015.9 } \mathrm{f} . \\
\text { Dissertação (Mestrado) - Curso de Políticas Públicas, Universidade Federal do Ceará, } \\
\text { Fortaleza, 2015. }\end{array}$ \\
\hline
\end{tabular}

\footnotetext{
${ }^{3}$ https://bdtd.ibict.br/vufind/
} 
Quadro 1: Trabalhos selecionados na plataforma BDTD. (continuação)

\begin{tabular}{|c|c|}
\hline D2 & $\begin{array}{l}\text { MEDEIROS, Josiane Lopes. O PIBID e a formação do professor de Ciências no } \\
\text { Instituto Federal Goiano - câmpus Rio Verde: avanços, limites e perspectivas. } 2015 . \\
196 \text { f. Dissertação (Mestrado) - Curso de Educação, Universidade Federal de Goiás, } \\
\text { Jataí, 2015. }\end{array}$ \\
\hline D3 & $\begin{array}{l}\text { OBARA, Cássia Emi. Contribuições do PIBID para a construção da identidade docente } \\
\text { do professor de química. 2016. } 120 \text { f. Dissertação (Mestrado) - Curso de Ensino de } \\
\text { Ciências e Educação Matemática, Universidade Estadual de Londrina, Londrina, } 2016 .\end{array}$ \\
\hline D4 & $\begin{array}{l}\text { DEMARI, Jennifer. A formação docente no Pibid/Química da UFRGS na perspectiva } \\
\text { dos egressos do Programa. } 2017.61 \text { f. Dissertação (Mestrado) - Curso de Educação em } \\
\text { Ciências, Universidade Federal do Rio Grande do Sul, Porto Alegre, } 2017 .\end{array}$ \\
\hline D5 & $\begin{array}{l}\text { CONDE, Ivo Batista. A prática docente de professores egressos do PIBID de } \\
\text { Biologia/UECE: Uma discussão à luz dos constructos de Paulo Freire. 2017. } 125 \mathrm{f} . \\
\text { Dissertação (Mestrado) - Curso de Educação, Universidade Estadual do Ceará, } \\
\text { Fortaleza, 2017. }\end{array}$ \\
\hline D6 & $\begin{array}{l}\text { FERNANDES, Andréia Matias. práticas de ensino de professores iniciantes de ciências } \\
\text { biológicas egressos do PIBID. 2018. } 134 \text { f. Dissertação (Mestrado) - Curso de } \\
\text { Educação, Universidade Estadual do Ceará, Fortaleza, } 2018 .\end{array}$ \\
\hline D7 & $\begin{array}{l}\text { GUARDA, Juliana Alves da. Programa Institucional de Bolsa de Iniciação à Docência: } \\
\text { Contribuições para a formação inicial e para a inserção na docência da educação } \\
\text { básica. 2019. } 160 \text { f. Dissertação (Mestrado) - Curso de Educação, Universidade Federal } \\
\text { de Goiás, Jataí, 2019. }\end{array}$ \\
\hline $\mathrm{T} 1$ & $\begin{array}{l}\text { GOES, Graciete Tozetto. O Programa Institucional de Bolsa de Iniciação à Docência - } \\
\text { PIBID - na avaliação dos licenciados da Universidade Estadual de Ponta Grossa, } \\
\text { egressos do programa. 2017. } 266 \text { f. Tese (Doutorado) - Curso de Educação, } \\
\text { Universidade Estadual de Ponta Grossa, Ponta Grossa, } 2017 .\end{array}$ \\
\hline $\mathrm{T} 2$ & $\begin{array}{l}\text { RIBEIRO, Marcus Eduardo Maciel. A formação de professores em comunidades de } \\
\text { prática por meio da participação no PIBID de química em instituições de ensino } \\
\text { superior no Estado do Rio Grande do Sul. 2017. } 251 \text { f. Tese (Doutorado) - Curso de } \\
\text { Educação em Ciências e Matemática, Universidade Católica do Rio Grande do Sul, } \\
\text { Porto Alegre, 2017. }\end{array}$ \\
\hline$T_{3}$ & $\begin{array}{l}\text { JESUS, Jairton Mendonça de. Efeitos do PIBID nos cursos de licenciatura do campus } \\
\text { professor Alberto Carvalho/UFS: Estudo comparativo entre egressos participantes e } \\
\text { não participantes do programa durante e depois da formação inicial. 2018. } 204 \text { f. } \\
\text { Tese (Doutorado) - Curso de Educação, Universidade Federal de Sergipe, São } \\
\text { Cristóvão, 2018. }\end{array}$ \\
\hline
\end{tabular}

Fonte: AUTORES, 2021.

Com o conjunto de 10 trabalhos que tratam sobre os egressos de cursos de Ciências da Natureza que participaram do Pibid, verificamos que sete (7) trabalhos são dissertações e três (3) teses. Identificamos também informações referente ao ano de 
publicação destes, em 2015 obtivemos dois (2) trabalhos de dissertação, em 2016 obtivemos um (1) trabalho de dissertação, em 2017 encontramos quatro (4) trabalhos, dentre estes, dois (2) de tese e dois (2) de dissertação, o ano de 2018 apresentou dois (2) trabalhos, sendo um (1) de tese e um (1) de dissertação, no ano de 2019 uma (1) dissertação foi encontrada.

Nos dez (10) trabalhos selecionados, averiguamos que estes apresentam predominantemente uma abordagem em campos diversos, ou seja, as pesquisas investigam a percepção dos egressos de diferentes cursos de licenciatura, incluindo cursos da área de Ciências da Natureza, conforme Gráfico 1.

Gráfico 1: Porcentagem dos trabalhos selecionados em relação ao curso de licenciatura.

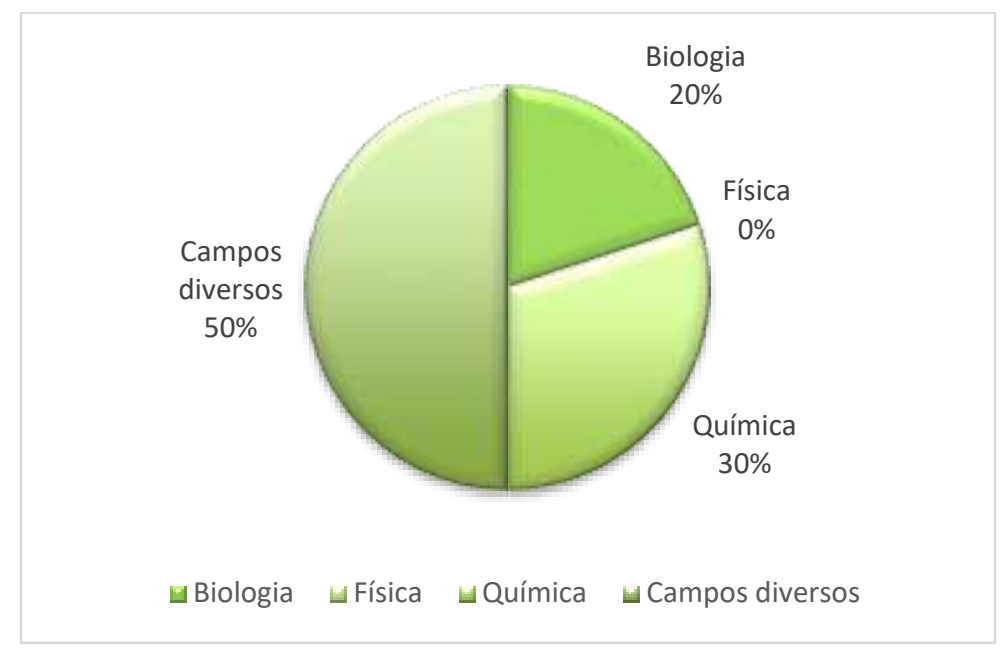

Fonte: Autores, 2021.

A partir do mapeamento dos trabalhos observamos a distribuição geográfica das produções. A região Sul obteve o maior número de trabalhos selecionados, já na região Norte não obtivemos nenhum trabalho selecionado, conforme apresentado no Gráfico 2.

Gráfico 2: Relação do número de trabalhos com as respectivas regiões do Brasil.

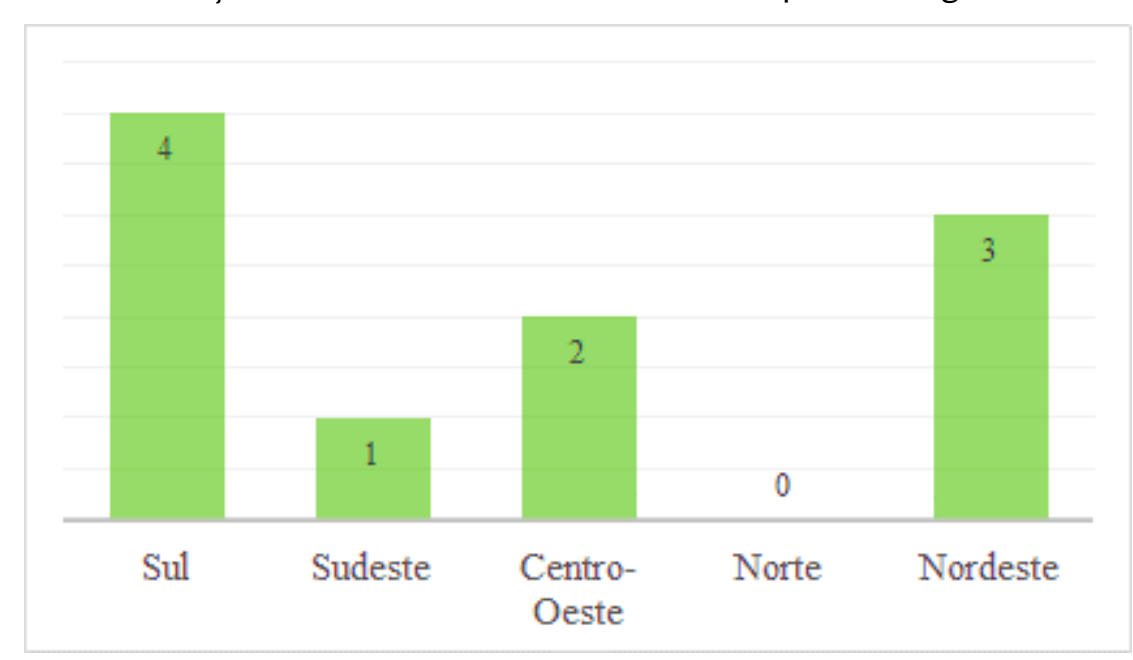

Fonte: Autores, 2021.

De acordo com estudo realizado por Gatti et al., (2014), essa diferença de 


\section{-Revista de Iniciação à Docência, v.6, n.2, 2021- \\ Publicação: dezembro, 2021 - ISSN 2525-4332}

trabalhos encontradas nas regiões se dá pelo fato de na Região Sul haver um maior número de coordenadores/formadores e supervisores contemplados nos editais do programa Pibid e na região Norte um menor índice de contemplação dessas bolsas.

Os trabalhos (dissertações e teses) selecionados evidenciam a potencialidade do Pibid para a formação de professores, destacando as marcas formativas que o programa deixa nos seus egressos. Por meio da análise, identificamos que estar inserido nas Escolas Básicas desde o início da docência têm implicações positivas, pois ao ir se ambientalizando com o espaço escolar o professor em formação inicial desenvolve novas perspectivas quanto ao ensino, incorpora a reflexão na sua formação e reinventa as formas de ensinar e de aprender.

Para Garcia (1999) políticas públicas que fomentam programas institucionais devem existir e são necessárias para estabelecer vínculos entre a formação inicial e o desenvolvimento da carreira profissional docente. Nesse sentido, André (2012, p. 128) cita que o Pibid é uma dessas políticas públicas que fazem a diferença na educação, porém adverte que o Brasil ainda tem "um longo caminho a percorrer", mas que o primeiro passo foi dado e os programas implementados em nosso país merecem valorização e mostram a pertinência destes para a qualificação da educação brasileira.

Nesse viés, Alves (2017) em seu trabalho de dissertação destaca que o Pibid não acaba com todos os problemas da educação, porém auxilia o desenvolvimento do professor iniciante, a autora aponta que mesmo com o programa

\section{[...] os problemas da inserção profissional continuam, e que os professores reconhecem esse fato, entretanto, a primeira aproximação com a escola propiciada pelo PIBID deixou uma construção profissional inicial que, se não é suficiente, favorece para que encarem com mais segurança o trabalho e os dilemas vivenciados nos primeiros anos de docência. As experiências significativas referem-se às aprendizagens da ação docente, ao desenvolvimento de projetos, ao domínio de como se alfabetiza, de como se lida com os alunos indisciplinados, à organização do planejamento, ou seja, como se conduz o trabalho na escola (ALVES, 2017, p.120).}

Assim, ressalta-se a importância do Pibid como um diferencial na formação inicial e um motivador de práticas diferenciadas, transformando o ensino e (re) significando a aprendizagem, sendo este um "terceiro espaço" de formação, que se caracteriza por reunir o conhecimento prático e acadêmico fornecendo subsídios para uma formação menos hierárquica e criando novas oportunidades de aprendizagens para os professores em formação (ZEICHNER, 2010).

Corroborando com isto, Bervian, Santos e Araújo (2019, p.443) refletem a

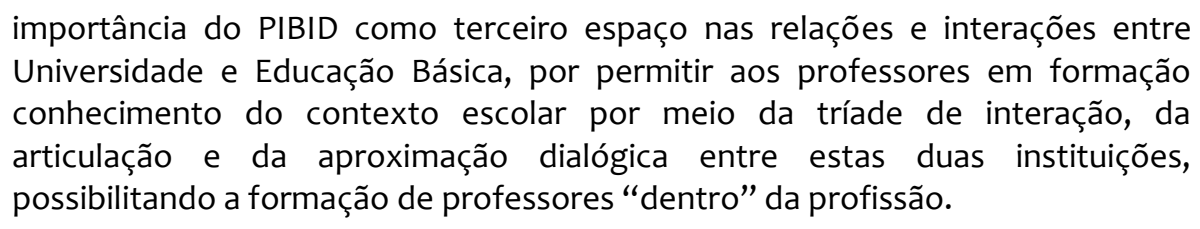

Após analisarmos as dissertações e teses selecionadas, organizamos as ideias 


\section{-Revista de Iniciação à Docência, v.6, n.2, 2021- \\ Publicação: dezembro, 2021 - ISSN 2525-4332}

principais abordadas nestes em categorias emergentes, para assim debatermos sobre os resultados da investigação e compreendermos as possíveis contribuições que o Pibid apresentou para os professores de Ciências da Natureza egressos do programa. Dessa forma, as categorias apresentadas são: I) Desenvolvimento da identidade profissional docente II) O Pibid como incentivo para a formação acadêmica e profissional.

\section{Desenvolvimento da Identidade Profissional Docente}

De acordo com os trabalhos selecionados, a inserção no Pibid proporciona a constituição de um professor pesquisador, o qual pensa sobre sua prática e a partir disso reinventa novos caminhos, novas alternativas de aprendizagem.

Conforme Pimenta e Ghedin (2002) ser um professor pesquisador diz respeito as reflexões realizadas durante as experiências práticas vivenciadas pelos professores em formação inicial e/ou continuada, construindo assim, novos conhecimentos, por meio da investigação da práxis.

Sendo assim, o professor ao tornar-se pesquisador desenvolve o senso crítico que favorece a autonomia profissional para a proposição de novas atividades.

Para André (2016, p.20)

o conceito de autonomia também está implícita a perspectiva de um sujeito social, com iniciativa, senhor de suas ações e de suas escolhas. Um sujeito que constitui sua identidade com base na relação com o outro nas trocas, na construção coletiva do conhecimento. Portanto, um sujeito interativo, que acolhe ideias alheias ao mesmo tempo em que constrói as Suas próprias. Nesse sentido, o conceito de professor pesquisador envolve uma perspectiva de colegialidade, de trabalho colaborativo.

Segundo a autora, a autonomia é desenvolvida por meio de um trabalho de pesquisa e investigação do professor para com a sua prática e a partir disso desenvolvemse ideias próprias oriundas das reflexões.

O Pibid com seu desenho e estruturação, colabora para uma educação transformadora, a qual seja significativa para os alunos e que também se configura numa perspectiva crítico-emancipadora, desenvolvendo professores autônomos e dispostos a realizarem uma educação para a emancipação e autonomia dos sujeitos. Dessa forma, o programa contribui para o desenvolvimento da identidade docente, ao oferecer um âmbito de formação e transformação pedagógica.

Nesse sentido, Errobidart e Rosa (2019) afirmam que as atividades realizadas pelos pibidianos, como a construção de aulas, são importantes para mobilizar os saberes que estes já possuem e construir novos saberes a partir do diálogo entre licenciandos, professores supervisores e coordenadores.

Nesta perspectiva Gatti et al. (2014, p.58) afirma que:

a possibilidade de experimentar formas didáticas diversificadas, de criar modos de ensinar, de poder discutir, refletir e pesquisar sobre eles são características 


\section{-Revista de Iniciação à Docência, v.6, n.2, 2021- Publicação: dezembro, 2021 - ISSN 2525-4332}

dos projetos Pibid ressaltadas como valorosas para a formação inicial de professores. Certa autonomia dada aos Licenciandos em suas atuações e em sua permanência nas escolas ajuda-os no amadurecimento para a busca de soluções para situações encontradas ou emergentes e para o desenvolvimento da consciência de que nem sempre serão bem-sucedidos, mas que é preciso tentar sempre.

Corroborando com este entendimento, podemos destacar o excerto do trabalho D5 (2017, p.34):

"ter uma preparação acadêmica pautada no desenvolvimento de profissionais reflexivos e cientificamente embasados pode proporcionar aos futuros professores maior autonomia e segurança para enfrentar os obstáculos e desafios com os quais inevitavelmente se deparar-se-ão na atuação docente".

No geral, os trabalhos selecionados mostram o diferencial que o Pibid proporciona aos participantes, destacando que o programa auxilia no desenvolvimento de aulas mais dinâmicas, criativas e inovadoras, visto que, os licenciandos desde o início do curso são oportunizados a experimentar a docência e aprender exercendo a profissão.

De acordo com as dissertações e teses selecionadas, os professores supervisores do programa apontam a articulação entre Ensino superior e Escola Básica como outro diferencial do programa, pois a partir dessa interação é possível que os professores em formação inicial e continuada compartilhem ideias e construam atividades em conjunto.

Estas atividades em parceria apresentam potencialidades para a constituição identitária docente, uma vez que oportunizam experiências enriquecedoras, que refletem na forma com que os professores iniciantes egressos do programa vão desenvolver suas aulas, possibilitando a esses segurança em relação à sala de aula (D2, D3, D6 e T3).

De acordo com Benites (2007) a identidade docente é processo de construção social, a qual é contínua e que se transforma na medida em que há necessidade de mudanças, inovações e (re) significações.

Nesse mesmo sentido, Garcia, Hypólito e Vieira (2005, p. 54-55) apontam que a identidade profissional dos professores se configura como

[... ] uma construção social marcada por múltiplos fatores que interagem entre si, resultando numa série de representações que os docentes fazem de si mesmos e de suas funções, estabelecendo, consciente ou inconscientemente, negociações das quais certamente fazem parte de suas histórias de vida, suas condições concretas de trabalho, o imaginário recorrente acerca dessa profissão $[\cdots]$.

Colaborando com este entendimento, o trabalho D4 (2017, p.54) destaca que o Pibid:

\footnotetext{
"ao oportunizar o enriquecimento da formação, através da inserção precoce no ambiente escolar,
} mostrando os tempos escolares, gera segurança aos bolsistas de iniciação à docência".

Nesse mesmo sentido, o trabalho T2 (2017, p.110) aponta que:

"as atividades em grupos, onde o trabalho coletivo e a convivência são fortes instrumentos de aprendizagem, podem estabelecer-se como fator de segurança aos licenciandos".

Nesse viés, destaca-se também a relação do programa com a construção da 


\section{-Revista de Iniciação à Docência, v.6, n.2, 2021- \\ Publicação: dezembro, 2021 - ISSN 2525-4332}

identidade docente, pois ao possibilitar a formação de um professor autônomo e que apresenta mais segurança em suas aulas, o Pibid também possibilita a construção de uma identidade docente por meio das reflexões, orientações, diálogos e parcerias.

Com relação a esse ponto, o trabalho D4 (2017, p. 54) afirma que:

"o momento da reflexão sobre a prática, a orientação nas atividades, são formas de contribuições citadas pelos egressos para a construção da sua identidade docente".

Dessa forma, evidencia-se que a inserção no Pibid se faz como um importante aliado para a formação docente, favorecendo aos futuros professores egressos do programa o desenvolvimento de suas aulas já no início da profissão. Nesse viés, Tardif (2000, p.14) infere que "os primeiros anos de prática profissional são decisivos na aquisição do sentimento de competência e no estabelecimento das rotinas de trabalho, ou seja, na estruturação da prática profissional”.

Sendo assim, ter uma formação inicial que possibilite a inserção no espaço escolar, tendo o suporte e a ajuda necessária dos professores do Ensino Superior e das Escolas Básicas é fundamental para o desenvolvimento profissional docente. Nesse sentido, as atividades no âmbito do Pibid refletem positivamente no trabalho do professor iniciante egresso do programa, proporcionando a este, autonomia e segurança.

\section{O Pibid como incentivo para a formação acadêmica e profissional}

O Pibid além de fornecer subsídios para a formação de um professor mais autônomo e seguro com relação a suas aulas, também é um incentivador para a formação acadêmica e profissional, promovendo em seus egressos a busca pela formação continuada.

Ser professor implica em formar-se continuamente (NÓVOA, 2009), dessa forma, a formação continuada deve se fazer presente no percurso formativo do professor, visto que, as transformações da sociedade, da ciência e das tecnologias exigem uma transformação do ensino também (KRASILCHIK, 2000).

Os egressos do Pibid destacam que a participação no programa incentiva a busca pela formação continuada acadêmica e profissional. Assim, grande parte dos egressos dos cursos da área de Ciências da Natureza continuam sua formação no mestrado e no doutorado e/ou realizando cursos especializados, participando de palestras, atividades formativas nas Escolas Básicas que trabalham e em algumas vezes se tornam professores supervisores do programa, auxiliando assim na formação de novos licenciandos e (re) significando o seu próprio fazer docente.

De acordo com os trabalhos selecionados, as atividades de pesquisa e relatos de experiência oportunizadas pelo Pibid auxiliam no interesse dos egressos em continuar suas investigações e também na seleção destes em cursos especializados. Tal afirmativa é apontada no trabalho D1 (2015, p.53):

"podemos afirmar que o contato com a pesquisa durante a formação inicial, incitada pelo PIBID no 
âmbito dos seus subprojetos, tenha despertado o interesse por futuras pesquisas".

Nessa perspectiva, o trabalho D7 (2019, p.119) também traz a afirmativa que:

"por meio do programa esse egresso aproximou-se da pesquisa em ensino e realizou mestrado nessa área, tornando-se um profissional mais preparado e confiante".

Os estímulos que o Pibid oferece aos seus participantes proporciona conhecimento e experiência, incentivando estes a participarem de eventos científicos, palestras, encontros, oficinas, seminários entre outros, refletindo assim, no currículo dos participantes, mas mais importante que isso, no crescimento pessoal e profissional destes, pois com as trocas de experiências é possível criar novas perspectivas e isto se torna um diferencial dos egressos do programa.

Em vista disso, Goulart et. al (2020, p.114) reitera que "na troca de experiências realizadas em sala, aprendemos muito mais do que ensinamos, cada qual com seu insumo, fomentando e discutindo, criando e ressignificando".

Assim, os trabalhos selecionados também demonstram o quanto o Pibid por meio de suas ações está fortalecendo a permanência na docência. Com isso o trabalho T1 (2017, p. 223) refere-se que:

"os objetivos do Pibid estão sendo atingidos, na medida em que, enquanto programa de formação inicial, ele favorece a compreensão da realidade escolar e valoriza a docência de maneira a incentivar a permanência na profissão. [.] A maioria dos egressos afirma que sua permanência na docência teve influência de sua participação no Pibid".

Nesse viés, as marcas formativas do Pibid apresentam uma importante contribuição para o desenvolvimento de seus egressos, proporcionando momentos de formação compartilhada e possibilitando a inserção destes em cursos de formação continuada, qualificando assim, cada vez mais a educação, além de fortalecer a permanência desses professores iniciantes na Escola Básica.

\section{Considerações finais}

A partir da análise dos dez (10) trabalhos selecionados identificamos que de acordo com as compreensões dos egressos o Pibid se configura como uma política pública de qualidade que incentiva a permanência na docência e contribui para um ensino de qualidade, formando professores habilitados, autônomos e mais seguros para o exercício da profissão.

O Pibid tem constituído uma formação diferenciada, na medida que proporciona interação antecipada dos professores em formação inicial na Escola Básica, permitindo assim, uma experiência formativa que preencha as lacunas da formação que somente com estágio supervisionado não é possível preencher.

A parceria colaborativa que o Pibid oferece enriquece a formação dos sujeitos envolvidos, possibilitando a troca de experiência e a produção de novos conhecimentos. Vale ressaltar também que, o programa incentiva a participação ativa em eventos 
científicos, feiras, seminários e congressos, motivando seus participantes a compartilharem conhecimento e enriquecer seus currículos e seu desenvolvimento profissional e pessoal.

Ao pesquisar o que as teses e dissertações estão destacando como contribuições do Pibid, também destacamos que o programa fornece subsídios para constituição da identidade docente de um professor reflexivo que aprende a partir de sua prática e que procura melhorar constantemente.

Enfatizamos que o programa, assim como outras políticas públicas, precisa de melhorias e de avanços. Porém, a existência do Pibid já é um grande começo de mudanças para a educação brasileira. Sendo assim, a permanência do programa é fundamental para qualificar a formação do professor, ao possibilitar a vivência com as Escolas e compreender na prática cotidiana o que é ser professor ao conhecer um pouco do universo da escola dos seus sabores e dissabores, das lutas e conquistas entre outras situações que perfazem o ambiente escolar. Todas essas experiências vão contribuindo com a constituição da identidade profissional.

Com os resultados do estudo, destacamos que os objetivos do programa estão sendo aos poucos alcançados, pois o Pibid tem fortalecido e valorizado a docência, na medida em que promove e qualifica a formação inicial e continuada de professores, além de despertar nos egressos a vontade de continuar na área do ensino de Ciências e da profissão de professor.

\section{Agradecimentos}

Agradecemos a Coordenação de Aperfeiçoamento de Pessoal de Nível Superior (CAPES) pelo financiamento da pesquisa.

\section{Referências}

ALVES, Roberlúcia Rodrigues. Professores iniciantes egressos do PIBID em ação: Aproximações à sua prática profissional. 2017. 136 f. Dissertação (Mestrado) - Curso de Educação, Universidade Estadual do Ceará, Fortaleza, 2017. Disponível em: https://bdtd.ibict.br/vufind/Record/UECE-o_b19ede48749dob924fgbc7cb3df21b50. Acesso em: 29 nov. 2020.

ANDRÉ, Marli. Política e programas de apoio a professores iniciantes no Brasil. Cadernos de pesquisa, v. 42, n. 145, p. 112-129, jan./abr. 2012. Disponível em: https://www.scielo.br/scielo.php?script=sci_arttext\&pid=S010015742012000100008\&lng=pt\&tlng=pt . Acesso em: 30 nov. 2020.

ANDRÉ, Marli. Práticas Inovadoras na Formação de Professores. Campinas: Papirus, 2016. 28op.

BARDIN, Laurence. Análise de conteúdo. São Paulo: Edições 70, 2011.

BDTD. Biblioteca Digital Brasileira de Teses e Dissertações. Disponível em: 
http://www.ibict.br/informacao-para-a-pesquisa/bdtd . Acesso em: 15 nov. 2020.

BENITES, Larissa Cerignoni. Identidade do professor de Educação Física: um estudo sobre saberes docentes e a prática pedagógica. 2007. 199f. Dissertação (Mestrado em Ciência da Motricidade). Instituto de Biociências, Universidade Estadual Paulista, Rio Claro-SP, 2007. Disponível em: https://repositorio.unesp.br/handle/11449/96058. Acesso em: 14 nov. 2020.

BERVIAN, Paula Vanessa ; SANTOS, Eliane Gonçalves dos ; ARAÚJO, Maria Cristina Pansera. O PIBID como terceiro espaço: elementos para formação de professores de ciências na profissão. Interfaces da Educação, v. 10, p. 423-444, 2019.

https://doi.org/10.26514/inter.v10i29.3441. Disponível em: <

https://periodicosonline.uems.br/index.php/interfaces/article/view/3441. Acesso em: 11 dez. 2020.

CAPES. Pibid - Programa Institucional de Bolsa de Iniciação à Docência. Brasília - DF, 2008. Disponível em: https://www.gov.br/capeseducacao-basica/capespibid. Acesso em: 20 nov. 2020.

DELIZOICOV, Demétrio; ANGOTTI, José André; PERNAMBUCO, Marta Maria Castanho Almeida. Ensino de ciências: fundamentos e métodos. São Paulo: Cortez, 2002. 364p.

ERROBIDART, Nádia Cristina Guimarães; ROSA, Paulo Ricardo da Silva. A construção de saberes docentes no contexto de ações formativas colaborativas. Revista Brasileira de Pesquisa Sobre Formação Docente, Belo Horizonte, v. 11, n. 20, p. 65-88, abr. 2019. Disponível em: https://revformacaodocente.com.br/index.php/rbpfp/article/view/191/190. Acesso em: 30 nov. 2020.

FELÍCIO, Helena Maria dos Santos. PIBID como "terceiro espaço" de formação inicial de professores. Revista Diálogo Educ., v. 14, n 42, p. 415-434, Curitiba/PR, 2014. Disponível em: https://periodicos.pucpr.br/index.php/dialogoeducacional/article/view/6587. Acesso em: 14 nov. 2020.

GARCIA, Marcelo. Formação de professores: para uma mudança educativa. Tradução Isabel Narciso. Portugal: Porto Editora, 1999.

GARCIA, Maria Manuela Alves; HYPOLITO, Álvaro Moreira; VIEIRA, Jarbas Santos. As identidades docentes como fabricação da docência. Educação e Pesquisa. São Paulo, v.31 n.1, pp.45-56, jan./mar. 2005. Disponível em:

https://www.scielo.br/pdf/ep/v31n1/a04v31n1.pdf. Acesso em: 28 out. 2020.

GATTI, Bernadete Angelina et al. Um estudo avaliativo do Programa Institucional de Bolsa de Iniciação à Docência (PIBID). Coleção Textos FCC, v. 41, p. 4-117, 2014. Disponível em: http://antigo.capes.gov.br/images/stories/download/bolsas/24112014-pibidarquivoAnexado.pdf. Acesso em: 24 out. 2020.

GOULART, J. B. da S. et al. Reflexões entre a prática e a teoria a partir de olhares de bolsistas do Pibid aplicados em escolas da rede pública municipal de Porto Alegre/RS. Revista de Iniciação À Docência, [S.L.], v. 5, n. 2, p. 103, 2 ago. 2020. Universidade Estadual do Sudoeste da Bahia/ Edicoes UESB. http://dx.doi.org/10.22481/riduesb.v5i2.7164. Disponível em: https://periodicos2.uesb.br/index.php/rid/article/view/7164. Acesso em:28 ago. 2020. 
IMBERNÓN, Francisco. Formação docente e profissional: formar-se para a mudança e a incerteza. $9^{\text {a }}$ ed. São Paulo: Cortez, 2011.127p.

KRASILCHIK, Myriam. Reformas e realidade: o caso do ensino das ciências. São Paulo em Perspectiva, v. 14, n. 1, p. 85-93, 2000. Disponível em:

https://www.scielo.br/scielo.php?script=sci_arttext\&pid=S0102-

88392000000100010\&lng=pt\&tlng=pt. Acesso em: 02 de dez. de 2020.

LUDKE, Menga; ANDRÉ, Marli. Pesquisa em Educação: Abordagens Qualitativas. São Paulo: EPU, 2013.

MIZUKAMI, Maria de Graça Nicoletti. Escola e desenvolvimento profissional da docência. In: GATTI, Bernadete Angelina. et al. Por uma política nacional de formação de professores. São Paulo: Unesp, 2013, p.23 - 54.

NOFFS, Neide Aquino; RODRIGUES, Regina Célia Cola. A formação docente: PIBID e Estágio curricular supervisionado. E-Curriculum, São Paulo, v. 14, n.1, p.357-374, 2016. Disponível em: https://revistas.pucsp.br/index.php/curriculum/issue/view/1567. Acesso em: 29 nov. 2020.

NÓVOA, Antônio. Para uma formação de professores construída dentro da profissão. Revista Educación, Madrid. n.350, set-dez, 2009. Disponível em:

http://www.revistaeducacion.educacion.es/re350_09.html. Acesso em: 1 dez. 2020.

PIMENTA, Selma Garrido. Práxis - ou indissociabilidade entre teoria e prática e a atividade docente. In.: PIMENTA, Selma Garrido. O Estágio na Formação de Professores: unidade teoria e prática? São Paulo: Cortez, 1994.

PIMENTA, Selma Garrido. Saberes pedagógicos e atividades docentes. 5. ed. São Paulo: Cortez, 2007.

PIMENTA, Selma Garrido; GHEDIN, Evandro. Professor reflexivo no Brasil: gênese e crítica de um conceito. São Paulo: Cortez, 2002.

SILVA, Kátia Augusta Curado Pinheiro Cordeiro da. A formação de professores na perspectiva crítico-emancipadora. Linhas Críticas. Brasília: v. 1 7, n. 32, p. 13-31, jan./abr. 2011. Disponível em:

https://repositorio.unb.br/bitstream/10482/9461/1/ARTIGO_FormacaoProfessoresPerspect iva.pdf. Acesso em: 07 mai. 2020.

SOCZEK, Daniel. Pibid como Formação de Professores: reflexões e considerações preliminares. Revista Brasileira de Pesquisa Sobre Formação Docente, Belo Horizonte, v. 3, n. 5, p. 57-69, ago. 2011. Disponível em:

https://revformacaodocente.com.br/index.php/rbpfp/article/view/46. Acesso em: 25 nov. 2020.

TARDIF, Maurice. Saberes profissionais dos professores e conhecimentos universitários: Elementos para uma epistemologia da prática profissional dos professores e suas consequências em relação à formação para o magistério. Revista Brasileira de Educação n.13, p. 05-24. 2000. Disponível em:

http://anped.tempsite.ws/novo_portal/rbe/rbedigital/RBDE13/RBDE13_05_MAURICE_TAR DIF.pdf. Acesso em: 21 nov. 2020.

ZEICHNER, Ken. Repensando as conexões entre a formação na universidade e as 
experiências de campo na formação de professores em faculdades e universidade.

Educação, v. 35, n. 3, p. 479-504, maio/ago. 2010. Disponível em:

https://periodicos.ufsm.br/reveducacao/article/view/2357. Acesso em: 25 jul. 2020.

$* * *$

Recebido: 24.06.2021

Aprovado: 13.12 .2021 